Lo que he tratado de mostrar en estas páginas ha sido, por un lado, la aportación del Romancero a la lírica popular moderna de un determinado esquema de construcción que la lírica no poseía, es decir, la influencia manifiesta de un género sobre otro. Por otra parte, he querido hacer resaltar el juego de fuerzas entre lo binario y lo terciario en la poesía tradicional, la tensión que puede crear y cómo, en este esquema particular, puede llegar a resolverse. También he querido señalar la constante relación entre forma y contenido y cómo la una conforma el otro y viceversa.

El Colegio de México.

Mercedes DíAz RoIG

\title{
SOBRE LA ANOTACIÓN DE LAS VISIONES DE TORRES VILLARROEL
}

E1 señor Luis López Molina, autor de artículos sobre la literatura del siglo $\mathrm{xx}$, ha dedicado una reseña a mi edición de las Visiones y visitas de Torres con don Francisco de Quevedo por la Corte, del gran satírico dieciochesco Diego de Torres Villarroel (Clás. cast., 1966); y a su recensión, impresa en 1972, en el tomo 20 (1971), 'pp. 149-153, de esta prestigiosa revista, me refiero en las líneas que siguen. Agradezco al señor López Molina sus amabilísimas palabras sobre la importancia y el rigor del texto que con mi edición se ha puesto a la disposición del lector, y le quedo asimismo muy endeudado por el entusiasmo con que ha comentado los capítulos tercero y quinto de mi Introducción, sobre el atraso científico y el estilo tradicionalista de Torres el uno, y sobre la visión del pecado a lo Hieronymus Bosch en las Visiones el otro. Lamento que el señor López Molina no se halle enteramente de acuerdo conmigo en las tesis de mis capítulos segundo y cuarto, referentes, éste a la forma seudomística de la relación Torres-Quevedo en las Visiones, y aquél a la forma híbrida ascético-picaresca de la Vida; para cuyo desacuerdo él no señala, sin embargo, ningún documento para oponer a los muchos que yo cito, ni ningún error concreto en mi documentación o interpretación de los pasajes de Torres allí analizados.

Mas no me mueve a redactar esta nota ni el desacuerdo en la interpretación de ciertos puntos de la estética torresiana, ni la vanidad (por-

riendo de rabia") ; en la versión III se ha convertido en elemento fundamental, que hace cambiar totalmente al tercer verso, desquiciado por el cambio de verbo en la versión II. Ahora se ha creado una unidad apretada entre los versos 3-4, que presentan un bloque sólido frente al bloque compacto de los versos 1-2. Se ha restaurado el equilibrio, y de una forma rota ha surgido una nueva forma que ya no es ni un esquema tripartito ni un esquema comparativo, sino un esquema igual al de muchas coplas cuya primera parte es independiente de la segunda, que es la que lleva la carga de contenido: "Las barandillas del puente/ se mimbrean cuando paso; / a ti solita te quiero, / de las demás no hago caso" (Guadalajara: VrrgarA, p. 217) ; "En el cielo no hay faroles, / que todo son estrellitas; / ¡bendita sea la madre / que te parió tan bonita!" (Aragón: Díaz, núm. 27). 
que en los seis años que han mediado entre la aparición de mi edición y la de la reseña de López Molina, han hablado de aquélla con el mayor favor distinguidos reseñadores españoles, franceses, americanos, etc., y en ella también han basado sus interpretaciones de Torres varios dieciochistas muy conocidos). El motivo que tengo para escribir este breve comentario es otro error mucho más alarmante que encuentro en las páginas del señor López Molina y del que podemos hablar de modo muy objetivo, por cuanto se relaciona con mi explicación (u omisión de explicación), en las notas, de ciertas voces y alusiones contenidas en el texto de Torres, y, cosa más importante aún, con la filosofía fundamental sobre la que vienen basándose desde hace siglos las buenas ediciones comentadas. López Molina demuestra un desconocimiento absoluto de tales criterios, pero el haber aparecido sus errados juicios en una revista tan justamente reputada parece sancionarlos, y si no se corrigen con la mayor brevedad, es muy de temer que induzcan a algún joven editor de textos clásicos a preparar un original inadmisible para las editoriales, o cuando menos intolerable para los lectores, por lo superfluo de las muchas notas innecesarias que contendría si se ajustara a ideas como las que se expresan en la referida reseña. Creo, por tanto, que las siguientes reflexiones y ejemplos pueden tener cierto valor como "manual negativo" de cómo se hace una edición comentada. Se basan por lo menos en la experiencia de quien se ha planteado el problema de cómo comentar, o por qué no comentar, casi toda suerte de voces y alusiones que quepa hallar en los textos clásicos, porque además de los cinco tomos del Fray Gerundio y las Visiones que he editado para Clás. cast., se publicó en 1971, en la Biblioteca Anaya, mi edición de la tragedia Numancia destruida de Ignacio López de Ayala, estoy terminando ahora de editar dos comediás de Tomás de Iriarte para Clásicos Castalia, y también tengo entre manos una edición de la Poética de Luzán para la colección de Textos hispánicos modernos de la Editorial Labor.

En la composición de las notas para "una edición no dedicada sólo a los especialistas sino a un público más amplio" - son palabras de López Molina (p. 152) -, bien es verdad que hace falta tomar en cuenta lo limitado de los conocimientos históricos, léxicos, geográficos, mitológicos, etc. del llamado lector general; mas al mismo tiempo es muy evidente que esos lectores generales que leen obras clásicas son los miembros más inteligentes y mejor preparados de ese "público más amplio" y que no hay que explicarles las cosas como habría que hacerlo con quienes no frecuentan más que las "Novelas del Coyote". Por consiguiente, existe una ley, no escrita las más veces, que no obstante ha sido obedecida casi siempre por los editores de libros clásicos para colecciones como Clás. cast. y Clásicos Castalia. Tal ley, conforme a la perenne práctica de los mejores editores, podría formularse así: No se ha de anotar voz alguna, o alusión alguna, histórica, filosófica, teológica, mitológica, científica, topográfica, etc. que el lector medianamente preparado pueda aclarar recurriendo a alguna de esas obras de consulta que suelen estar a mano en las casas particulares o en las más pequeñas bibliotecas públicas: esto es, el DRAE, el Pequeño Larousse Ilustrado, quizá (en el caso de un lector extranjero de un clásico español) un buen diccionario bilingüe, 
una enciclopedia abreviada, mapas y planos modernos de los principales países y ciudades, etc.

Que yo sepa, no se han referido por escrito a este principio más editoriales que Anaya y Labor, la primera en unas Instrucciones generales para los colaboradores de la Biblioteca Anaya, en donde se lee: "Se evitará comentar voces, giros, alusiones geográficas, mitológicas, históricas, etcétera, que el lector pueda descifrar consultando un diccionario"; y la segunda en un Memorándum para uso de los editores de los tomos de la colección Textos hispánicos modernos, en el que "se recomienda no agobiar el texto con notas que expliquen aspectos que pueda resolver cualquier diccionario o enciclopedia manual". Yo recibí estas instrucciones de Anaya y Labor respectivamente en los años 1965 y 1968; mas desde hacía muchos años ya venían ateniéndose a tales criterios, aunque con ciertas salvedades, incluso los editores de ediciones destinadas sólo a los filólogos, para quienes no se deja imaginar banquete más exquisito que el mayor acopio posible de notas sobre toda suerte de particularidades léxicas, etimológicas, semánticas, morfológicas, fonológicas, etc., por impertinentes que resulten para el lector interesado en el sentido general o arte del libro anotado.

Vamos ahora a aplicar estas ideas a los juicios de López Molina sobre mis notas a las Visiones de Torres. "En cuanto a las alusiones a las calles, edificios o plazas de Madrid -escribe el reseñador comentando mi anotación de los mismos-, unas veces son objeto de explicaciones detalladas y otras carecen por completo de ellas" (p. 153). Ahora bien, las calles, las plazas y los edificios comentados son los siguientes: la Casa de los Consejos, la calle de la Platería, la plazuela de Palacio, las calles de Jacometrenzo (grafía y recorrido antiguos) y de Foncarral (grafía antigua), el Real Hospicio de San Fernando, el convento de la Victoria, la iglesia de San Sebastián, la calle ancha de los Peligros (diferente de la actual de los Peligros), la plazuela y convento de San Gil, la plazuela de San Juan, la parroquia de San Martín, el convento de San Felipe el Real, la iglesia del Buen Suceso, la plazuela y teatro de los Caños del Peral, el Seminario de Nobles, el Colegio Imperial, el convento de San Camilo de Lelis, el Coliseo del Buen Retiro, la cuestecilla de los Caños de Peral, el Santo Monte de Piedad y la Real Librería. Se trata de calles y sitios en su mayoría totalmente desaparecidos, o cuyos nombres o uso han cambiado; por eso se los ha comentado. En cambio, no están comentadas las calles del Caballero de Gracia, del Príncipe, de la Cruz, del Postigo de San Martín, del Carmen, de las Postas y de Hortaleza, ni la Red de San Luis, ni la Puerta del Sol, ni la plazuela de la Cebada, ni el Prado, evidentemente porque casi no pasa semana sin que todo madrileño recorra o a lo menos oiga mencionar la mitad de ellos, y porque el lector que no haya visitado Madrid fácilmente los hallará en el más humilde y barato plano de la Corte, pues todos ellos existen todavía, con los mismos nombres, y algunos ni aun están muy cambiados de aspecto.

Basé mi anotación de los sitios públicos de Madrid en una minuciosísima comparación del plano dieciochesco de Madrid debido a Fausto Martínez de la Torre (nueva edición de 1800), citado en mis notas, con varios planos modernos, y en varios libros, como El antiguo Madrid de 
Mesonero Romanos, también citados en mis notas; pero para que aun así no se omitiese ninguna explicación que hiciera falta al lector general, en el otoño de 1965, antes de entregar mi original a la imprenta, hice un viaje especial a Madrid, donde recorrí dos veces el camino de Torres y "Quevedo" por la capital española, con el plano de Martínez de la Torre en una mano y un plano moderno en la otra. Hace sesenta años, al preparar su edición de la Vida de Torres para "La Lectura" (después Clás. cast.), don Federico de Onís se guió precisamente por esos mismos criterios, aunque entonces estaban completamente inéditos, y así aparecen en su edición de la autobiografía torresiana, sin ninguna anotación, los nombres de las todavía existentes calles de la Rúa, de Salamanca (p. 80), de Alcalá (p. 90), del Pez (p. 93), de Fuencarral (p. 93) y la Puerta del Sol (p. 88), de Madrid (cito por la impresión de 1954). Asimismo, en la edición de Clás. cast. del Pedro Sánchez de Pereda, preparada por el director de la misma colección, don José María de Cossío, aparecen sin ninguna nota las madrileñas calles y plazas del Olmo (t. 1, p. 113), de la Cebada (t. 2, p. 25), de la Montera (t. 2, p. 116), etc. (cito por la impresión de 1958). López Molina dice, a continuación del "reparo" ya citado, que "hubiese sido fácil subsanar" esta clase de "deficiencia" en mis notas. Pero ya queda claro que tal "deficiencia" no es más que una ilusión padecida por el señor López Molina en virtud de su falta de experiencia en la preparación y aun en la lectura de las ediciones comentadas.

Por sí solo todo alumno undergraduate de español en Estados Unidos descubre que si no encuentra al pie de la página la explicación de una palabra o nombre que le haya resultado incomprensible o irreconocible, se trata sin embargo, en la mayoría de los casos, de algo comúnmente conocido, y acude sin máśa su Pequeño Larousse. Así, en las notas a un texto clásico, no habría que identificar a Góngora, Jáuregui ni Moreto, aun cuando algún lector tuviese que consultar su Pequeño Larousse sobre el segundo, pero sí habría que incluir una nota sobre el olvidado poeta Francisco Mosquera de Barnuevo o el igualmente desconocido jurisconsulto Antonio Pichardo Vinuesa, ambos del Siglo de Oro. Lamento tener que decir cosas tan obvias; pero, por otra parte, si los "eruditos" que reseñan libros para las revistas más respetadas no se hacen ya cargo de ella, ¿qué es lo que podremos esperar del lector general o del estudiante dentro de varios años? Recuerdo que una vez, en mi clase de literatura dieciochesca, hablé como diez minutos de la oda de Quintana $A$ Juan de Padilla antes de darme cuenta de que cierto estudiante perezoso, aun habiendo leído todo el poema, no tenía la menor idea de quién pudiese ser aquel señor, porque entre las notas de la edición de Clás. cast. el editor, Narciso Alonso Cortés, no había creído necesario dar las fechas y demás pormenores biográficos referentes al conocidísimo patriota español, y porque así habría sido necesario tomarse el trabajo de acudir al Pequeño Larousse. ¿Empieza a formarse ahora una generación de hispanistas profesionales de la misma estirpe, nueva generación de eruditos a la violeta, para usar el término dieciochesco?

Pero vengamos ya a lo más esencial en toda edición comentada: la aclaración de aquellos elementos léxicos que puedan ocasionar dificul- 
tades al lector moderno. Carece en absoluto de lógica el siguiente aserto de López Molina: en las notas a mi edición -dice- "se hace uso excesivo de las definiciones del Tesoro de Covarrubias y del Dicc. Aut., las cuales, aunque mantienen un tono de época acorde con el texto de Torres, acaban por imprimir un tono arcaizante algo pesado" (p. 153). Para cualquiera debía ser evidente que los anotadores de textos antiguos nos vemos forzados a tomar las definiciones de las voces arcaicas de los diccionarios donde se encuentren; no somos libres para variar el estilo de las notas, como se hace en un ensayo con los sinónimos, empleando a voluntad en cada pasaje el diccionario por el que más nos encaprichemos en el momento, ni para evitar "un tono arcaizante algo pesado" en ciertas notas consultando diccionarios modernos en los que no se comenten las palabras necesitadas de aclaración; y, por otra parte, ¿cómo vamos a tener los anotadores la culpa de que los dos mejores instrumentos que tenemos para conocer el léxico español del Siglo de Oro y el setecientos, y por ello los dos más frecuentados en todas las ediciones comentadas, sean precisamente el Tesoro de Covarrubias y el Dicc. Aut.? (Ya sabe cualquier lector que haya manejado mi edición que no obstante todo esto también he consultado para mis notas otros muchos diccionarios y fuentes de diversas clases, alguna muy rara).

Hablando ya de las que él quiere ver como lagunas concretas en mis notas léxicas, Molina afirma que en éstas "se echa de menos la explicación de una serie de voces o expresiones nada fáciles" (p. 152), y en su nota 4, referente a estas palabras, sigue diciendo: "Lo necesitado de explicación puede ser la voz misma o bien uno de sus sentidos. A título de ejemplo, entresaco algunos casos tomados de la primera parte de la obra, indicando la página y línea en que se encuentran: avutardado 11.2, sura 15.13, columpios 20.25, moharraches 26.2 , perillán vitela 28.4, hambreón 28.18, indiciados 29.10, chisguete 29.14, gregueria 32.5 , diviso 47.16, engaitadores 50.3, médico nordeste, 54.2, tubas falopianas 59.5 , tolanos 69.13 , gambas 72.5 , celibato 73.9 , salinas 82.24 , almagrados 98.16, estornudos occidentales 99.10". Ahora bien, en el mismo sentido en que los usa Torres en los pasajes indicados por Molina, aparecen los vocablos sura, en el $D R A E$; diviso, en el $D R A E$ y el Pequeño Larousse; engaitador, en el DRAE y el Spanish and English Dictionary de Williams (el Pequeño Larousse tiene engaitar, de donde facilísimamente se deduce el sentido de engaitador); e indiciar ( $>$ indiciados), tolanos y celibato, en los tres diccionarios de la Academia, Larousse y Williams. (Escogí este último diccionario como ejemplo de los bilingües por ser el mejor de los de esta clase impresos en los Estados Unidos; el mejor diccionario bilingüe español-francés, español-italiano, etc. arrojaría sin duda aproximadamente los mismos resultados numéricos, aun cuando no se encontrasen en él las mismas voces). En fin, seis sobre las diecinueve palabras y expresiones mencionadas por López Molina (casi la tercera parte) no pueden producir el más mínimo problema para el lector más tardo con tal que consulte el diccionario.

Otras siete voces de la lista de Molina se encuentran definidas en los diccionarios en un sentido muy próximo al que les da Torres, y del que fácilmente se deriva su significado exacto, sobre todo con la ayuda del 
contexto torresiano: gamba, en el DRAE; avutardado, en los diccionarios de la Academia y Williams; y columpio, moharrache, chisguete, gregueria y almagrar (> almagrados), en los tres diccionarios de la Academia, Larousse y Williams. En el único de estos casos en el que me parecía que aun consultando los diccionarios la voz podía seguir resistiendo a la interpretación (moharrache), he incluido una nota para aclarar el sentido exacto que tiene en el pasaje donde ocurre, y allí incluso ilustro mi explicación con un texto de otra obra de Torres; pero al señor López Molina se le habrá olvidado leer las notas impresas al pie de mi p. 26.

Confundirse, en la descripción de un ser humano, ante la sustitución de pierna por gamba ('parte del animal entre el pie y la rodilla o comprendiendo el muslo', según el $D R A E$, ed. de 1970) es no haber entendido nada del simbolismo animal bosquiano que está presente en alguna forma en casi cada una de las descripciones torresianas. En un pasaje en el que se habla de dormir mucho, avutardado 'semejante a la avutarda', no puede significar más que 'tardo, pesado', por ser tal ave de "vuelo corto y pesado", según el DRAE (además, avutardado incluso contiene tardo). El lector de un texto clásico no tarda en descubrir la necesidad de consultar las definiciones lo mismo de las raíces que de los derivados, como se ve una vez más por el ejemplo de columpios, que cuando Torres sacude violentamente a Quevedo, es evidente que se refiere a los "movimientos del cuerpo de un lado a otro", acepción que tiene columpiar en ciertos casos y que está registrada en los diccionarios. Entre los andrajos que vestía cierta figura en las Visiones "se descolgaba un chisguete de camisón"; en donde chisguete 'trago, chorrillo' tiene el evidentísimo sentido metafórico de 'tira'. (Al lector inteligente no hay que explicarle sino las metáforas más difíciles, y las notas tienen que hacerse pensando en el más inteligente de los lectores generales, como se ha dicho antes). Gregueria, 'gritería confusa de la gente' según los diccionarios, en la frase torresiana "la descuadernada greguería de oficios que hay en la Red de San Luis", resulta claro que alude a los gritos de quienes venden sus productos por la calle de la Montera y esa parte de Madrid, y quizá por extensión tenga a la vez el poquísimo menos evidente sentido de "la desordenada variedad" de tales oficios. Almagrados < almagrar, que los diccionarios definen como 'teñir de almagre [que, como sabe todo el mundo, es de color rojizo], es obvio que significa 'enrojecidos' cuando se describe a unos borrachos "muy almagrados de cachetes, ardiendo las mejillas en rescoldo de tonel", etc.

Las seis frases y voces de la lista de Molina que no están en los diccionarios (o que aparecen en ellos con acepciones ni aun remotamente relacionadas con las que tienen en Torres) tampoco pueden presentar ningún problema salvo en un caso. El perillán vitela es un pícaro que tiene el cutis como pergamino: las dos voces están en todos los diccionarios, y el contexto sugiere muy claramente tal interpretación. (Si hubiésemos de explicar todas las metáforas de esta clase contenidas en las descripciones de las Visiones, las notas tendrían tres o cuatro veces más extensión que la obra misma; y disfrutaríamos mucho menos en su lectura, pues el arte descriptivo de Torres depende en gran parte de la sorpresa del lector al reconocer por sí mismo los objetos comunes bajo 
las formas inverosímiles de que se los reviste en las "visiones" del ingenioso satírico). En el período: "Todo era indicio de estómago en pena, de tripas en vacante y de hambreón descomunal", ¿qué puede ser hambreón sino un aumentativo de hambre, con retención de la vocal $e$ para distinguirlo del adjetivo hambrón, y por ende, qué sentido puede tener sino el mismo de 'hambre grande o extrema' que tienen las voces hambrina, hambruna y hambrusia? Aunque me parecía muy deseable explicar la expresión médico nordeste, como no se me sugirió ninguna aclaración que fuera posible confirmar, preferí no correr el riesgo de desorientar al lector con una solución que pudiese resultar falsa. La voz salina, ¿qué sentido puede tener sino el mismo que sal 'agudeza, donaire', cuando Torres dice, dirigiéndose a Quevedo: "Las festivas pimientas y tus abundantes salinas, cuando igualmente vestías la pluma de mojarrilla y de toga, ya no hay quien las guste"? La tuba lo mismo que la trompa es un instrumento de viento, y así no parece probable que a ningún lector general se le haga difícil entender por tubas falopianas los oviductos, que acostumbramos llamar trompas de Falopio.

Por fin, ninguno de cuantos alumnos he tenido, ni españoles, ni hispanoamericanos, ni angloamericanos, se ha confundido por el sentido de la expresión estornudos occidentales en el siguiente trozo de la descripción torresiana de un banquete de glotones, uno de los cuales "con el vendaval de un regüeldo, apagó una de las luces. Otro disparó mucha artillería de estornudos occidentales". Si yo' hubiese puesto un sabio escolio diciendo que "por lo visto no puede tratarse sino de una furiosa descarga de los que, con perdón del lector, en lenguaje vulgar, suelen apellidarse pedos o ventosidades y se producen por la repentina expulsión de los gases intestinales", ¿no habría merecido la crítica mucho más de lo que la merezco habiendo callado? Una nota sobre tal pasaje sería digna de un pedante de la categoría de ese famoso don Hermógenes, personaje de La comedia nueva de Moratín. ¡Cómo se habría reído también el mismo doctor don Diego de Torres Villarroel, siempre tan consumado artista de lo escatológico, si hubiese podido leer el "reparo" que me pone el reseñista por haber omitido comentar la "expresión nada fácil" de estornudos occidentales!

Russell P. SEbold

University of Pennsylvania.

\section{ESTUDIOS SOBRE EL MODERNISMO *}

Bajo el título Estudios criticos sobre el modernismo, Homero Castillo nos ofrece una recopilación de unos veinte textos críticos sobre el

* Acerca de los siguientes volúmenes:

Guileermo Díaz-Plaja, Las estéticas de Valle-Inclán. Gredos, Madrid, 1965. (BRH, Estudios y ensayos, 85).

Ned J. Davison, The concept of modernism in Hispanic criticism. Pruet Press Inc., Boulder, Colorado, 1966. 